\title{
«... EN LA CAMPAÑA SE HA DESPERTADO UN ESPÍRITU MALIGNO». ESTRATEGIAS POLÍTICAS Y DIVISIONES SOCIALES EN LAS PRIMERAS ELECCIONES MUNICIPALES (ESTADO DE BUENOS AIRES, 1855)
}

\author{
Mariana Canedo \\ Universidad Nacional de Mar del Plata-CONICET \\ (Mar del Plata, Argentina) \\ ORCID: https://orcid.org/0000-0001-8368-7909 \\ mcanedo@mdp.edu.ar
}

Proponemos analizar las tensiones puestas de manifiesto en las primeras elecciones de municipales realizadas durante el Estado de Buenos Aires como parte de la implementación extensiva de la nueva forma de gobierno en la campaña. Buscamos integrar la normativa y las discusiones en las Cámaras Legislativas con prácticas situadas en diferentes partidos de la campaña, para considerar la complejidad del proceso durante todo el año 1855. Argumentamos que las elecciones municipales en la campaña activaron tensiones sociales de las comunidades locales, desafios perennes de los poderes centrales con el gobierno de la campaña e imaginarios políticos más recientes sobre el mundo rural, en un estado soberano atravesado por enfrentamientos y debates sobre la construcción del estado-nación.

PALABRAS CLAVES: Elecciones municipales, campaña - Estado de Buenos Aires, divisiones sociales, estrategias politicas.

«... IN The Countryside a malignant SPIRIt has aWAKED». Political StRategies AND SOCIAL DIVISIONS IN THE FIRST MUNICIPAL ELECTIONS (ESTADO DE BUENOS AIRES, 1855)

This paper aims at analyzing the tensions expressed in the first elections of municipales made during the Estado de Buenos Aires as a part of the extensive implementation of the new form of government in the countryside. It looks for an integrated approach with the norms and the discussions in the Legislative chambers with practices located in different local districts from the countryside as a way to consider the complexity of the process throug- 
hout 1855. The objective consists of demonstrating that the municipal elections in the countryside activated social tensions of the local communities, perennial challenges of central powers with the government of the countryside and more recently politic imaginaries on the rural world, in a sovereign state crossed by confrontations and debates on the state building.

KEYWORDS: Municipal elections, countryside - Estado de Buenos Aires, social divisions, political strategies.

\section{A Juan Carlos, por compartir su pasión y sensibilidad por la práctica histórica}

En mayo de 1855, un proyecto solicitando la postergación de «la instalación de las municipalidades en la ciudad y campaña hasta el año entrante» fue discutido en la Cámara de Diputados del Estado de Buenos Aires. Con anuencia del gobierno, el diputado Emilio Agrelo lo presentaba a dos meses de haberse realizado las primeras elecciones de municipales en la ciudad y en unos 45 pueblos de la campaña. El diputado argumentaba que después de haber sido éstas practicadas, se había despertado «un espíritu maligno», en la campaña y algunas elecciones habían «recaído en personas indignas», categoría en la que incluía a «ladrones y mashorqueros». ${ }^{1}$ Agrelo añadía que en la ciudad se había producido «un abandono completo de espíritu público». ${ }^{2}$

En la sesión, como ya había sucedido en el debate sobre la Ley de Municipalidades en octubre de 1854, algunos diputados consideraron las «dificultades de todo género» del proceso de instalación del nuevo gobierno local. ${ }^{3}$ No obstante, puntualizaban que no había fecha de implementación establecida por la ley ni por las Cámaras Legislativas y que era «el Gobierno» (en el sentido de poder ejecutivo) quien «tenía que preparar el terreno» e «iba a sentir las dificultades». ${ }^{4}$ El proyecto fue finalmente retirado por el autor,

1. Diario de Sesiones de la Cámara de Diputados del Estado de Buenos Aires (Diputados), Acta de la sesión de 16 de mayo de 1855 (16/05/1855), Buenos Aires, Imprenta Americana, 1856, pp. 31-35.

La Mazorca fue una organización política que tuvo un papel central en la violencia ejercida para amedrentar a los opositores al gobernador de Buenos Aires, Juan Manuel de Rosas, y evitar fraccionamientos entre los propios federales. En el acta de la sesión figura «mashorqueros», en referencia a los integrantes de la «más horca», una de las acepciones nominales que acentuaba la amenaza. Sobre la organización y usos dados a la Mazorca en diferentes coyunturas, puede verse: González Bernaldo, Pilar Civilidad y política en los orígenes de la nación argentina, Buenos Aires, Fondo de Cultura Económica, 2007, pp. 220-224; Di Meglio, Gabriel, Mueran los salvajes unitarios. La Mazorca y la política en tiempos de Rosas, Buenos Aires, Sudamericana, 2007; Eujanian, Alejandro, El pasado en el péndulo de la política. Rosas, la provincia y la nación en el debate político de Buenos Aires, 1852-1861, Bernal, Universidad Nacional de Quilmes, 2015, pp. 119-139.

2. Diputados ..., cit., p. 31.

3. Durante el siglo XVIII y primeros años del siglo XIX, los pueblos habían tenido una limitada adjudicación de prerrogativas, no logrando convertirse en villas y acceder al autogobierno. A su vez, cuando los cabildos de la villa de Luján y de la ciudad de Buenos Aires fueron suprimidos en 1821, sus atribuciones fueron asumidas por el gobierno provincial. Es decir, en toda la jurisdicción de la provincia de Buenos Aires no hubo institución local elegida por los vecinos por más de treinta años.

4. Diputados..., cit., pp. 31-32. 
pero lo debatido allí permite considerar aspectos del desafío político que significaba la municipalización del territorio del recientemente conformado Estado de Buenos Aires.5 ¿En qué consistía la complejidad adjudicada por los legisladores a la «instalación» de las municipalidades de campaña? ¿Qué había sucedido en las primeras elecciones municipales sustanciadas en 1855 para que se solicitara su postergación?

El conocimiento sobre el caso del Estado de Buenos Aires (1854-1861), una de las experiencias soberanas o «separatista», en Hispanoamérica decimonónica es todavía fragmentado. ${ }^{6}$ Los enfrentamientos entre la Confederación Argentina y Buenos Aires suelen ser la clave de lectura por antonomasia del periodo y, si bien su relevancia es indiscutible, consideramos que tiende a eclipsar las experiencias de gobierno desarrolladas en cada configuración estatal. ${ }^{7}$ Las investigaciones actuales consolidan la idea de un ciclo de enfrentamientos entre alianzas heterogéneas y cambiantes que depusieron o limitaron a los líderes que fueron ejerciendo el poder (Juan Manuel de Rosas, Justo José de Urquiza, Valentín Alsina). ${ }^{8}$ Durante los primeros años del Estado de Buenos Aires, facciones, grupos y personalidades con trayectorias políticas diferentes se habrían aunado en la ciudad con los objetivos de poder enfrentar a la Confederación, lograr la gobernabilidad interna en el nuevo estado soberano y posicionarlo en un lugar protagónico en la organización del estado nacional. ${ }^{9}$ En esta perspectiva, la campaña de Buenos Aires quedaba considerada como un reducto federal y mazorquero. ${ }^{10}$

5. Por municipalización de la campaña nos referimos al proceso de conformación de gobiernos locales en forma simultánea y extensiva (40 pueblos de la campaña), a los que se asignó una cantidad relevante de potestades. Canedo, Mariana, «La instalación de las municipalidades de campaña en el Estado de Buenos Aires. Un análisis desde sus actas de sesiones (1856-1858)», Revista de Historia Americana y Argentina, 54-1,Mendoza, UNCuyo, 2019, pp. 177-209.

6. No obstante, cada vez contamos con más investigaciones sobre problemáticas del período. Entre los clásicos se destaca, Scobie, James, La lucha por la consolidación de la nacionalidad argentina, 1852-1862, Buenos Aires, Solar-Hachette, 1964.

7. Sobre la incidencia de los conflictos, gastos militares y movilización de personas en la Confederación y Buenos Aires, característica compartida por los estados decimonónicos. Garavaglia, Juan Carlos, La disputa por la construcción nacional argentina. Buenos Aires, la Confederación y las provincias (1850-1865), Buenos Aires, Prometeo, 2015.

8. Caletti Garciadiego, Bárbara, «Después de la tormenta cla calma?: Ejército y milicias en la campaña porteña tras Caseros», Coordenadas, 1, 2014, pp. 59-89; Eujanian, Alejandro, El pasado..., cit.; Aramburo, Mariano, Concepciones en torno a la conformación del Estado, Buenos Aires 1852-1862, Tesis doctoral, UBA, 2015: de Jong, Ingrid y Ratto, Silvia, «La construcción de redes políticas indígenas en el área Arauco-pampeana: la Confederación indígena de Calfulcurá (1830-1870)», Interseccione, 9, Olavarría, 2009, pp. 241-260; Barcos, Fernanda «Expresiones políticas y movilización popular en los pueblos de la campaña de Buenos Aires. La Guardia de Luján y el Sitio de Lagos (1852-1854)», Nuevo Mundo, Mundos Nuevos, 2012 (en línea) Consultado el 24 de mayo de 2017, pp. 1-19 y «Tratos, batallas y malones. El accionar indígena en la frontera sur durante el sitio a la ciudad de Buenos Aires», Corpus, vol. 7, núm. 1, 2017, pp. 2-30; Cancini, Leonardo, Frontera, militarización y política armada. La Guardia Nacional de la Provincia de Buenos Aires durante la construccion del Estado Nacional (1852-1880), La Plata, AAAPBA, 2017 entre otros.

9. Sobre los usos de la categoría facciones, Etchechury-Barrera, Mario e Ignacio Zubizarreta, «Aquí no hay partidos»: Estudios y perspectivas sobre las facciones y grupos políticos del siglo XIX hispanoamericano», Illes e imperis, núm. 17, 2015, pp. 7-17.

10. El análisis en profundidad de este argumento, en Eujanian, A., El pasado..., cit., pp. 13-109. 
La implementación del régimen municipal para todo el territorio constituyó una cuestión central en la organización interna del Estado de Buenos Aires. ${ }^{11}$ El objetivo del artículo es analizar las tensiones puestas de manifiesto en las primeras elecciones de «municipales y suplentes» como parte de la implementación extensiva de la nueva forma de gobierno en la campaña del Estado de Buenos Aires. Las analizaremos a partir de la normativa y la diversidad de las prácticas, desde un ángulo que busca articular diferentes ámbitos y coyunturas, y considerar la variedad de actores y perspectivas que surgieron en torno a estas primeras elecciones municipales durante 1855.

Argumentamos que las primeras elecciones municipales en la campaña activaron tensiones sociales de las comunidades locales, desafíos perennes de los poderes centrales con el gobierno de la campaña e imaginarios políticos más recientes sobre el mundo rural en Buenos Aires, en un estado atravesado por enfrentamientos y debates en torno a la construcción del estado-nación. Diferentes actores articularon estrategias buscando asentar el control sobre el territorio y la población rural del Estado de Buenos Aires.

Hace quince años, Juan Carlos Garavaglia elegía una perspectiva local de las elecciones en la campaña, para profundizar el conocimiento de las luchas políticas y los conflictos sociales para la primera mitad del siglo XIX. ${ }^{12}$ Por ese sendero, buscamos contribuir a la comprensión de los mecanismos empleados para la constitución de las municipalidades de campaña, a la vez que iluminar cómo se fue configurando un nuevo ordenamiento político y social en el Estado de Buenos Aires.

\section{Las primeras elecciones municipales}

Durante el siglo XIX, las prácticas eleccionarias en Hispanoamérica fueron importantes en la legitimación de los gobernantes, asociadas a los conceptos de soberanía popular y representación política. ${ }^{13}$ En el Río de la Plata, su importancia se puso de manifiesto desde la primera década revolucionaria, por lo que a mediados del siglo XIX resultaban me-

11. Registro Oficial del Gobierno de Buenos Aires (ROGBA), Constitución del Estado de Buenos Aires, Buenos Aires, Imprenta de Mayo, 1854, p. 45, art. 170. Los gobiernos provinciales de la Confederación fueron los encargados de organizar las municipalidades, y lo hicieron en forma paulatina.

12. Garavaglia, Juan Carlos, «Elecciones y luchas políticas en los pueblos de la campaña de Buenos Aires: San Antonio de Areco (1813-1844)», en Boletín del Instituto de Historia Argentina y Americana «Dr. Emilio Ravignani, núm. 27, Buenos Aires, 2005, pp. 49-73. Una continuación de esta línea para la campaña, son los trabajos de Lanteri, Sol, «¿Una frontera bárbara y sin instituciones? Elecciones y clientelismo en la formación del Estado provincial durante el gobierno de Rosas» y Santilli, Daniel, «El unanimismo en la campaña. Las actividades políticas en la xona rural de Buenos Aires entre Rivadavia y Rosas. Quilmes, 1821-1839», ambos en Prohistoria, núm. 12, Rosario, 2008, pp. 15-40 y 41-67, respectivamente; Galimberti, Agustín, «Las prácticas electorales coloniales y la conformación de un "habitus" electoral: el Cabildo de la Villa de Luján entre 1771 y 1821», Prohistoria, núm. 29, 2018, pp. 43-67.

13. Una síntesis de esta prolífera y consolidada línea de investigación, enfocada hacia mediados del siglo XIX y con las referencias bibliográficas principales, en: Sábato, Hilda, «Los desafíos de la República. Notas sobre la política en la Argentina pos Caseros», Estudios Sociales, XXIV, 46, 2014, pp. 77-117. 
canismos habituales en los procesos políticos. ${ }^{14}$ Como ha sido señalado, lo novedoso en la Confederación Argentina a partir de 1853, residió en la incorporación del voto directo de los ciudadanos a elecciones periódicas con carácter nacional (diputados al Congreso y electores de presidente y vicepresidente), además de continuarse con las provinciales. ${ }^{15}$ En el Estado de Buenos Aires, observamos que además de las elecciones bicamerales de diputados y senadores, fueron las elecciones de municipales para la ciudad y la campaña las que marcaron un cambio.

En febrero de 1855, ante el «restablecimiento sólido de la paz» y el «regreso de los vecinos a sus hogares», el gobierno del Estado de Buenos Aires estipuló oportuno dar cumplimiento a la Ley de Municipalidades y llevar a la práctica los beneficios que reportarían «al país» estas nuevas formas de gobierno en «todo el Estado». ${ }^{16}$ Las primeras elecciones para la ciudad fueron convocadas para el 25 de febrero y para las municipalidades de campaña, el 11 de marzo.

Eran elecciones directas en las que los vecinos de cada «partido» (jurisdicción local rural en Buenos Aires) elegían en esa primera oportunidad cuatro municipales y dos suplentes. Los elegidos se renovarían por mitades en elecciones anuales. ${ }^{17} \mathrm{~A}$ esta frecuencia electoral se le agregaron las elecciones «parciales» para cubrir cargos ante las renuncias o fallecimientos de municipales que se producían en cualquier momento del año, por lo que el tiempo dedicado a estas prácticas políticas varió según el caso, aunque en conjunto fue relevante.

En la normativa y las modalidades de organización, las elecciones no presentaban mayores modificaciones en relación a las de períodos anteriores o a las que se venían realizando para diputados y senadores en el Estado de Buenos Aires. ${ }^{18} \mathrm{El}$ encargado del acto electoral en cada partido siguió siendo el juez de paz, con la colaboración de los tenientes y alcaldes de los diferentes cuarteles y los escrutadores nombrados para examinar el desarrollo del comicio. Sin embargo, señalamos dos diferencias que tendrán sus respectivas consecuencias, como veremos más adelante. Mientras que la unidad jurisdiccional para diputados/senadores era la sección electoral integrada por un número variable de partidos cercanos, en las elecciones municipales fue cada partido y la población aveci-

14. Garavaglia, Juan Carlos, «Manifestaciones iniciales de la representación en el Río de la Plata: la Revolución en la laboriosa búsqueda de la autonomía del individuo (1810-1812), Revista de Indias, núm. 23, Madrid, 2004, pp. 349-382; Ternavasio, Marcela La revolución del voto. Política y elecciones en Buenos Aires, 1810-1852, Siglo XXI, Buenos Aires, 2002. Sobre la importancia de las culturas políticas previas, Galimberti, Agustín, «Las prácticas electorales...», cit., pp. 43-68.

15. Sabato, H. «Los desafíos...», cit., p. 34.

16. Los fundamentos del decreto hacían alusión a la incursión desde Rosario de federales exiliados liderada por el General Gerónimo Costa en noviembre de 1854, rápidamente derrotado, y a los Pactos de Convivencia firmados a fines de diciembre y principio de enero entre la Confederación y Buenos Aires. ROGEBA, Decreto 09/02/1855, p. 12.

17. El artículo 60 de la Ley de Municipalidades establece lo correspondiente a la elección de diputados como referencia para las municipales. ROGBA, Ley de Municipalidades, 1854, p. 116 y Reglamento de Municipalidades de Campaña, 1856, p. 9

18. Ternavasio, La revolución ..., cit., para la campaña, Garavaglia, «Elecciones y luchas...». 
nada en él. Además, en vez de la respectiva cámara legislativa, fue el gobierno —en la figura del ministro de gobierno y el gobernador- quién estableció las fechas de realización y quien aprobaba cada elección.

Como se había estipulado, en marzo de 1855 se realizaron las elecciones en más de 40 partidos. Una parte de ellas parece haberse efectuado sin mayores inconvenientes y al día siguiente cada juez de paz elevó los registros y actas al ministro de gobierno. Al mes, a través de un decreto con la firma del gobernador y el ministro de gobierno, se aprobaron las elecciones para municipales y suplentes practicadas en 38 partidos. ${ }^{19}$ Asimismo, se tuvo en consideración algunos «defectos» señalados en algunos lugares y se convocó a nuevas elecciones en esos partidos para el 6 de mayo. El panorama presentado por el ministro de gobierno con las tres cuartas partes de los partidos con elecciones municipales aprobadas eclipsa las prácticas eleccionarias y los conflictos suscitados, a la vez que no se condice con la solicitud de suspensión de las mismas por parte del diputado Agrelo. Presentamos a continuación dos casos de elecciones municipales aprobadas, que permiten problematizar el panorama.

\section{Disturbios en la mesa electoral de San Nicolás de los Arroyos}

El partido de San Nicolás de los Arroyos ubicado en el extremo norte de la provincia, constituyó uno de los más poblados de la campaña (8.450 personas, según registro de 1854). Había obtenido el título honorífico de ciudad en 1819, aunque sin conformar el gobierno correspondiente. Su población estuvo involucrada de manera directa en las disputas entre la Confederación Argentina y el Estado de Buenos Aires, por su cercanía con las provincias de Santa Fe y Entre Ríos.

En 1854, la dinámica de la comisión municipal fomentada hasta la conformación de las municipalidades de campaña en base a la elección del propio juez de paz de sus seis integrantes, puso en evidencia el compromiso de un grupo de vecinos en pos de lograr el funcionamiento de un gobierno colegiado local. ${ }^{20}$ En marzo de 1855, la elección de municipales fue aprobada y se estableció una continuidad entre los integrantes de la comisión y la municipalidad. No obstante, aun en este contexto, el juez de paz de San Nicolás de los Arroyos informó al ministro de gobierno sobre el intento de «atropellar la mesa, apoderándose de las actas y despedazarlas». La acción fue emprendida por «algunos individuos en muy corto número y notable por su escasa representación» ante «el rechazo

19. ROGEBA, Decreto 11/04/1855, pp. 54-55, artículo 1.

20. Canedo, Mariana «La instalación...». Durante el gobierno de Rosas, se consideró que en San Nicolás había una presencia relativamente importante de «unitarios». Gelman, Jorge, «Crisis y reconstrucción del orden en la campaña de Buenos Aires. Estado y sociedad en la primera mitad del siglo XIX», Boletín del Instituto de Historia Americana y Argentina» Dr. Emilio Ravignani, núm. 21, 2000, pp. 7-31 y «Unitarios y federales. Control político y construcción de identidades en Buenos Aires durante el primer gobierno de Rosas, Anuario IEHS, núm. 19, 2004, pp. 359-391. 
que la mesa y el Pueblo hicieron de la candidatura de D. Pedro Regalado Rodríguez por faltarle la calidad de vecino». ${ }^{21}$

Descendiente de la familia fundadora de San Nicolás, Pedro Regalado Rodríguez (y Aguiar) había estado vinculado a Rosas durante todo su gobierno, compartiendo tempranas expediciones a la frontera o siendo su secretario en la ciudad de Buenos Aires. Tras Caseros, fue el encargado de organizar los papeles del ex gobernador y pasó a revistar en la Plaza Mayor como militar inactivo a fines de 1853. En agosto de 1854 fue elegido diputado por la 10. ${ }^{a}$ sección de la campaña, que incluía a los partidos de San Pedro, Baradero y San Nicolás (en las elecciones legislativas la residencia no fue considerada como requisito). De todas formas, su pertenencia al círculo cercano a Rosas pareciera haber sido lo que produjo el mayor resquemor al grupo de vecinos afianzados en el gobierno local de San Nicolás.

Asimismo, Jacinto González, «uno de los principales instigadores», tuvo una «moderada pena correccional de 24 horas de arresto» por haber insultado a integrantes de la mesa electoral. El juez de paz generó los fundamentos para que González fuese enrolado y remitido a la frontera, pero también solicitó orientación al ministro «a fin de evitar también a que los procedimientos del Juzgado sean atribuidos a causa política». El 13 de abril, González fue detenido por estar en una casa de juego y luego destinado al Servicio de las Armas del Regimiento de Blandengues.

Los comportamientos descriptos no eran prácticas inusuales pero se expresaban con componentes propios de los años posrosistas. En este caso, limitando a un referente provincial del rosismo en el nivel local donde un activo grupo lo respaldaba. ${ }^{22}$ También, se ejemplifica una modalidad del accionar del juez de paz interactuando con miembros del gobierno para enrolar a determinados sujetos hacia la frontera y que su accionar no fuese considerado «político».

\section{La «determinación patriota» del juez de paz de Cañuelas}

Las primeras elecciones municipales en el partido de Cañuelas fueron realizadas el 1. ${ }^{\circ}$ de abril, en vez del 11 de marzo como estaba dispuesto. En dos comunicaciones paralelas, el juez de paz Evaristo Alfaro explicó su decisión de postergarlas. Al ministro de gobierno, le señaló su «ataque de la enfermedad al estomago» y la falta de actas para realizar el acto eleccionario. ${ }^{23} \mathrm{Al}$ gobernador, en una carta particular, Alfaro especificaba haber retenido el juzgado de paz por quince días, ya que ante la proximidad de las elec-

21. AGN, Archivo del ministro de gobierno del Estado de Buenos Aires (en adelante MGEBA), Sala X, 28-6-14, 9607. El artículo 59 de la Ley de Municipalidades establecía que los cuatro miembros de la municipalidad y sus dos suplentes serían vecinos del partido, mayores de 25 años o emancipados, tendrían un capital de al menos diez mil pesos o profesión, arte u oficio que les permitieran contar con una renta equivalente.

22. Hay referencias a un grupo que quiere sacar a González de la cárcel, a la circulación de panfletos en San Nicolás sobre el proceder del juez de paz, entre otros indicios sobre lo activo del grupo.

23. AGN, MGEBA, X 28-6-14, 9577. 
ciones municipales había comenzado a «desentrañarse un círculo» sobre «mi excelente, aunque débil sucesor». ${ }^{24}$ Se había armado una lista para Cañuelas y Alfaro expresaba su posición:

Penetrado de las ideas que tuve el honor de oír de boca del Gobierno, sobre la importancia que daba al resultado de esta elección que debe ser completamente de hombres nuestros, adictos a la actualidad de Corazón, ¿con qué sorpresa no recibiría la adjunta lista en la que veo figurar a D. José Abraguin, Juez de Paz de Rosas y hombre de antecedentes tan fatales, a D. Pedro Gajon, su secretario, y amigo muy intimo?25

Cañuelas había sido un baluarte del rosismo. Ubicado a unos $70 \mathrm{~km}$ al sudoeste de la ciudad de Buenos Aires, el partido se había consolidado durante la primera mitad del siglo XIX, con una clara orientación ganadera y población relativamente dispersa. Pocos pobladores habían sido considerados unitarios a principios de la década de 1830 o habían tenido embargados sus bienes en 1840; la participación de votantes en las elecciones de 1839 y 1840 en Cañuelas había sido de las mayores de la campaña. ${ }^{26}$

El gobernador Pastor Obligado respondió a los dos días, en el mismo tenor particular, aplaudiendo la «determinación patriota» de Alfaro. ${ }^{27}$ Ante el posible triunfo de la mayor parte de las candidaturas anunciadas, proponía «que todos los buenos patriotas se pongan de acuerdo con anticipación y trabajen con empeño, a fin de burlar las pretensiones a los enemigos encubiertos del País y del actual orden de cosas». Obligado adelantaba la nueva fecha de elecciones y que confiaba que Alfaro influiría «en todos sus amigos para que la elección recaiga en personas adictas a la causa de la libertad, del orden y de los principios». La comparación entre la lista que el juez de paz señalaba como circulando en el partido para las elecciones del 11 de marzo, con los municipales y suplentes electos el 1. ${ }^{\circ}$ de abril pareciera mostrar que el juez de paz cumplió el objetivo.

24. Las atribuciones de los jueces de paz fueron cambiando según las coyunturas. Tuvieron un funcionamiento clave en el rosismo, fundamentalmente a partir de 1840, aumentando la permanencia en sus cargos. Fradkin, Raúl y Jorge Gelman, Juan Manuel de Rosas. La construcción de un liderazgo político, Buenos Aires, Edhasa, 2015, pp. 325-328. La tendencia se modificó durante el Estado de Buenos Aires, predominando la rotación de jueces, aunque con diferencias en las zonas de frontera.

25. De la lista que circulaba, Alfaro exceptuaba al Sr Don Diego Arana por sus antecedentes honorables y consideraba a los demás como hombres «incapaces completamente, ni de comprender su misión» ni de oponerse a las tendencias disolventes que pudiese abrigar ese círculo.

26. Gelman, Jorge, «Unitarios y federales...», cit., p. 371; Ternavasio, Marcela, «Hacia un régimen de unanimidad. Política y elecciones en Buenos Aires, 1828-1850», en Sábato, H. (coordinadora), Ciudadanía política y formación de las naciones, México, FCE-El Colegio de México, 1999, p. 136.

27. En ambas cartas se evitó hacer referencia a los cargos de gobernador y juez de paz; el trato fue de Señor y de Don, acompañado por «De mi mayor aprecio y respeto» por parte de Alfaro y «Estimado compatriota» por parte de Obligado. Ambas firmas fueron antecedidas por la fórmula de tinte cordial «S.S. y amigo». AGN, MGEBA, X, 28-6-14, 9631. 
CuAdro 1. Elecciones municipales, Cañuelas 1855.

\begin{tabular}{ll}
\hline Lista Circulante (MARZO) & MuniciPales EleCtOS (ABRIL) \\
\hline José Abraguin & Diego Arana \\
Pedro Gajón & Francisco Lalama \\
Juan Barreda & Mariano Cebey \\
Diego Arana & Manuel Carranza \\
& \\
Suplentes: & Suplentes: \\
Juan García & Julián Rosquellas \\
Julian Rosquellas & Juan Arana \\
\hline
\end{tabular}

Elaboración personal.

FuENTE: AGN, MGEBA, X 28-6-14, 9631 y ROGEBA, Decreto 22/11/1855.

De todas maneras, la situación debió ser sostenida: en enero de 1856, cuando se iban a implementar las municipalidades, Carranza, Lalama y Rosquellas quisieron excusarse del cargo, lo que no fue aceptado por el ministro de gobierno; en junio de 1856, en una elección parcial ante la renuncia de un municipal, fue votado José Abraguín (el ex juez de paz del rosismo), aunque minoritariamente. ${ }^{28}$

El cruce de documentación ha permitido recuperar la importancia dada por «el Gobierno» a estas primeras elecciones municipales, a partir del eco de alguna arenga o la correspondencia con el propio gobernador, así como las consecuentes acciones emprendidas por el juez de paz. Las consideraciones de lo patriótico, una referencia continua en la sociedad rioplatense desde los procesos independentistas, aludían a una causa superior aglutinadora que se activaba «en el actual orden de cosas». ${ }^{29}$

\section{Nuevas elecciones para las municipalidades de campaña}

En términos generales, como venimos señalando, el decreto del 11 de abril aprobaba los resultados de gran parte de las elecciones (entre las que se incluían las de San Nicolás y Cañuelas), pero aclaraba que se procedería a nuevas elecciones en siete partidos, quedando otros pendientes..$^{30}$ ¿Por qué se tomaba esta resolución? Se consideraba que, según las

28. MGEBA, Sala X 28-10-4, 13048.

29. Di Meglio, Gabriel, «Patria», en Golman, Noemí, Lenguaje y revolución. Conceptos políticos claves en el Río de la Plata, 1780-1850, Buenos Aires, Prometeo, 2008, p. 191. Sobre el ideal fusionista en la visión del «patriótismo liberal», ver Caetano, Gerardo, «Patria. La Patria resignificada tras los "lenguajes del Patriotismo"» en: Caetano, Gerardo (coord.), Historia conceptual. Voces y conceptos de la política oriental (1750-1870),

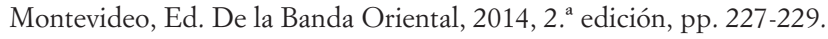

30. El gobierno esperaba contar con información sobre los resultados en otros seis partidos del «sur» (en 
comunicaciones de los jueces de paz o las protestas formuladas por «muchos vecinos», en algunos partidos habría habido algunos defectos («varios electos inhábiles según la Ley» o por el modo en que se había procedido en la votación). La nueva convocatoria era considerada el mejor medio para «conciliar la paz y armonía entre los vecinos de un mismo Municipio». ${ }^{31}$ Presentamos la reconstrucción de varios casos para comprender mejor los «defectos» encontrados en estas prácticas electorales.

\section{El escrutinio del juez de paz a los electos en San José de Flores}

Al día siguiente a haberse realizado la votación de marzo, el juez de paz de San José de Flores comunicó al ministro de gobierno dos observaciones sobre los municipales y suplentes electos. Fabio Pereyra no tenía «más edad que la de 19 a 20 años», por lo que el juez de paz no lo creía «apto para desempeñar el delicado cargo de Municipal». ${ }^{32}$ Asimismo, el juez de paz llamaba la atención del ministro sobre la elección de Isidro Silva, el último juez de paz de Rosas en el partido. Por último, consideraba que «Sr. Domingo Olivera no admitirá el cargo de Municipal por parte de los individuos electos, no serán de su confianza».

San José de Flores había constituido otro sitial de adhesión al rosismo. Lindante con la ciudad de Buenos Aires, las vías mercantiles de San José de Flores vinculaban la ciudad y el puerto con otras zonas. El partido presentaba una orientación productiva cerealera y frutihortícola y una estructura agraria diversificada que durante el rosismo se acentuó a través de una política de ventas y adjudicaciones de tierra a distintos sectores. ${ }^{33}$ Hilario Lagos se había asentado allí durante el sitio de grupos federales a la ciudad en 1853 .

Pareciera que el informe del juez de paz bastó para que las elecciones de marzo no fueran aprobadas para San José de Flores. No obstante, al repetirse la elección en mayo, Isidro Silva —el ex juez de paz de Rosas - nuevamente fue quien obtuvo más votos (83), en una elección bastante pareja. Silva había sido un activo juez de paz. Además del compromiso político con el rosismo, mientras fue autoridad local se emprendieron obras relevantes para el lugar (pavimento del camino central; ampliación del cementerio, etc.).

zona de frontera), para resolverlos. El caso de Lobería aparecía con «obstáculos insuperables para practicar las elecciones» ROGEBA, Decreto 11/04/1855, pp. 54-55, artículo 3.

31. Los siete partidos señalados en el decreto fueron San José de Flores, San Fernando, San Isidro, las Conchas, Chascomús, San Antonio Areco y Tandil (artículo 2). Sin embargo, también se realizaron nuevas elecciones en algunos de los partidos supuestamente aprobados, como Mercedes.

32. El día de la elección se había presentado como emancipado por tener un empleo en la «Comisión Topográfica», pero el juez averiguó que había sido «un escribiente» y que lo habían «expulsado». AGN, MGEBA,X, 28-10-5, 13075.

33. La fuerte adhesión al rosismo de la población se condice con el registro de la relación de 258 federales y 43 unitarios informada para 1830/1831. Varias familias percibidas como unitarias fueron embargadas en 1840 . Gelman, Jorge, «Unitarios y federales...», p. 371. Ciliberto, Valeria, «Patrimonio y producción en los entornos rurales de Buenos Aires. San José de Flores, 1800-1875», Mundo Agrario, núm. 15, La Plata, 2007, pp. 34-56. 
A diferencia del juez de paz de Cañuelas, el de San José de Flores había actuado sobre los resultados de la elección, no pudiendo evitar que Silva fuese electo. Sin embargo, al día siguiente de la segunda elección, Silva se excusó por «razones y motivos graves y atendibles de salud» y su solicitud fue aceptada. Los otros vecinos observados por el juez de paz, no se encontraron entre los nuevos elegidos.

\section{Los «vecinos» de Las Conchas y las «personas extrañas a este lugar»}

Las nuevas convocatorias a elecciones municipales no siempre fueron promovidas por un juez de paz. En Las Conchas, tras comunicar que la elección de marzo había sido realizada «con estricto ajuste a la Ley de la materia», el juez de paz elevó al ministro de gobierno un «documento firmado por algunos vecinos» que había sido «remitido anoche a este Juzgado» por medio de «un sirviente». ${ }^{34}$

El partido de Las Conchas, a unos $40 \mathrm{~km}$ al norte de la ciudad de Buenos Aires, articuló su conformación en torno al dinámico puerto homónimo sobre el Río de la Plata. Era considerado un «centro comercial de importancia» donde comerciantes destacados de Buenos Aires habían instalado allí representantes desde fines del siglo XVIII. ${ }^{35}$

Solo nueve vecinos firmaban la nota que había sido escrita, según exponían, desde la iglesia del pueblo ${ }^{36}$ Consideraban ilegales las elecciones por «vicios y nulidades» y fundamentalmente cuestionaban al juez de paz por no haber permitido votar a los extranjeros que concurrieron a hacerlo, quienes se habían tenido que retirar tras clasificaciones ofensivas a su nacionalidad; el rechazo al voto de los vecinos de otros «cuarteles» que no fuese el del pueblo; y, la presencia de «personas extrañas» que habían ido «a tomar parte activa para la elección, elevando su voz y entrando a intervenir y a clasificar el derecho de los vecinos concurrentes oponiéndose a que diesen su voto muchos de ellos».

Los nueve vecinos pedían que se realizara una nueva elección respetando los derechos de los extranjeros avecinados y las demás disposiciones señaladas, y finalizaban haciendo saber al juez de paz que también enviaban una nota al «Superior Gobierno». En esta comunicación expresaron que habían «sido privados de su sufragio infinitos vecinos a quienes la ley» les condecía el derecho, y que

la excitación de la concurrencia, animada por algunas personas con gritos de mueran los gallegos y gringos, la violencia del cabo de Policía despojando a muchos vecinos de la lista de su

34. AGN, MGEBA, X, 28-8-7, 11453.

35. Archivo Histórico de Geodesia y Catastro, Duplicado de mensura, Partido de Tigre, No 10, p. 5. Canedo, Mariana, «Pueblos frente al río. Comercio fluvial, poder colonial, y derechos a la tierra Buenos Aires, 1770-1820», Bibliográphica Americana. Revista interdisciplinaria de Estudios coloniales, núm. 8, 2012, pp. 69-93.

36. Los vecinos firmantes fueron J. Pérez Mendoza, Manuel Lynch, S. V. Rynel, Zacarías Iparraguirre, Fortunato Navarro, Faustino Navarro, Bernardo Daiasco, Eduardo Rosales, Bernardino Roseti, a los que se agregó en la nota al gobierno, Matías Majesté. 
elección por otras que les entregaba para que votaran por ella, la voz dominante y la acción imponente de los que rodeaban la mesa, personas sin domicilio en este destino y por consiguiente sin voto electivo. ${ }^{37}$

La presencia en el acto electoral de grupos que querían votar, sin residir en la jurisdicción, y que con presencia física y gritos buscaban desalentar el voto ajeno, constituía una práctica conocida que implicaba la existencia de articulaciones sociales y políticas que las emprendían, como vimos para San Nicolás. Tampoco era nuevo el uso de adjetivaciones con finalidad despectiva hacia los extranjeros asentados en la zona, muchas veces asociado a sus rasgos económico-sociales. ${ }^{38}$ Justamente, el partido de Las Conchas se caracterizó por contar con una población en torno a los 960 pobladores durante todo el siglo XIX, con una incidencia relativamente importante de extranjeros vinculados a las actividades comerciales. ${ }^{39}$

Las notas presentadas a las autoridades por estos nueve vecinos que evidencian en sus comportamientos una posición social destacada, formaban parte de las prácticas de petición o representación usuales en el mundo rural rioplatense, entre otros ámbitos hispanoamericanos. En estos casos constituían un instrumento que, sin ser electoral, permitía impugnar o modificar una elección. ${ }^{40}$ Si bien describían situaciones violentas que los vecinos habían vivido, el lenguaje no estaba orientado a la búsqueda de protección por parte de la autoridad, y menos con el juez de paz. Los vecinos se distanciaban de una relación de subordinación y se presentaban como sujetos soberanos que interpelaban al gobierno, es decir a sus representantes, para restaurar el orden, sus derechos y el cumplimiento de la ley en las elecciones municipales del partido en el que residían.

Sin embargo, la nueva elección se realizó en mayo con cambios limitados en los resultados.

37. Se señalaba que al llegar la hora de procederse al escrutinio, «y como esta operación resultase la mayoría a favor de la lista por la que votaban los que suscriben, no acomodando este resultado ni al Juez de Paz ni a sus adictos» hicieron continuar la votación «dando listas confeccionadas en el acto».

38. Garavaglia, Juan Carlos, «Pobres y ricos»: Cuatro historias edificantes sobre el conflicto social en la campaña bonaerense (1820/1840)», en Poder, conflicto y relaciones sociales. El Rio de la Plata, XVIII-XIX, Rosario, Homo Sapiens, 1999, pp. 29-56; Pérez, Mariana En busca de mejor fortuna. Los inmigrantes españoles en Buenos Aires desde el Virreinato a la Revolución de Mayo, Buenos Aires, Prometeo-UNGS, 2010. La relación entre federales y unitarios hacia 1839 fue pareja, y hubo pocos embargos en el partido.

39. La información de las planillas del censo de 1854 es limitada, pero permite considerar que el $10 \%$ de la población en el partido era extranjera (21 españoles, 11 ingleses, 12 franceses, 15 italianos, 2 norteamericanos, 2 alemanes, 6 portugueses y 20 de «otras nacionalidades»). Entre ellos, 8 eran «comerciantes», 22 «artesanos», 57 jornaleros y 3 en «otras ocupaciones». Asimismo, entre los «porteños» y los «provincianos» se encontraban «hacendados» $\mathrm{y}$ «agricultores», junto con «artesanos» $\mathrm{y}$ «militares», dependientes de comercio, peones y «diversas ocupaciones». Registro Oficial de Estadísticas, 1854, Planilla 10.

40. Galimberti, Agustín, «Las prácticas electorales...», cit., p. 57. 
CUADRO 2. Elecciones municipales, Las Conchas 1855.

\begin{tabular}{ll}
\hline Marzo (CUESTIOnADA) & \multicolumn{1}{c}{ MAYo (nUeVA) } \\
\hline Prudêncio Dolz & Salvador Hernandez \\
Salvador Hernandez & Jose Maria Bustos \\
Juan Francisco Alcorta & Juan Francisco Alcorta \\
José Maria Bustos & Agustín Martínez \\
& \\
Suplentes: & Suplentes: \\
José Maria Romero & Jose Maria Romero \\
Manuel Brid & Manuel Brid \\
\hline
\end{tabular}

Elaboración personal.

FuENTES: AGN, MGEBA, X 28-8-7, 11453 y ROGEBA, Decreto 22/11/1855.

Solo Prudencio Dolz dejó de ser elegido y a cargo de la elección se encontró un juez de paz «sustituto» (Juan Francisco Alcorta, electo en ambas oportunidades).

\section{«Vecinos» de San Fernando y una elección «con toda legalidad»}

En San Fernando, el partido aledaño a Las Conchas y también vinculado a una importante dinámica mercantil fluvial, el juez de paz comunicó al ministro de gobierno que la documentación de la elección había sido sustraída de la casa del juzgado el domingo a la noche. Aclaraba que «nada se ha podido averiguar» y solicitaba instrucciones. ${ }^{41}$

Tres días después, 87 «ciudadanos vecinos» solicitaron al gobierno (en términos de «V.E.», vuestra excelencia) que no se anulase la elección realizada «con toda legalidad». Argumentaban que las actas habían sido firmadas y selladas antes de haber sido extraídas del juzgado, y que el gobierno tenía medios de inquirir sobre la situación y el juez de paz podía informar al respecto. Caracterizaban al hecho como «escandaloso», pero consideraban que «si esta elección se llegase a anular sería un golpe que recibiría la institución en su principio» por lo que pedían «se sirva acceder a nuestra solicitud, por ser justicia».42

La petición de los vecinos de San Fernando no prosperó y en mayo se realizó la nueva elección con 205 votantes. Al comparar los resultados de ambas elecciones, se observa claramente cómo los elegidos en marzo fueron desplazados, con excepción de Manuel Moura.

41. AGN, MGEBA, X 28-8-7, 11455. La presencia federal en San Fernando fue un poco más marcada que en Las Conchas durante el rosismo.

42. La petición de los vecinos de San Fernando se diferenciaba de los de Las Conchas no solo por los términos de su formulación. Los «vecinos» parecieran tener otro perfil social, entre los firmantes de San Fernando hay un alcalde de cuartel y un teniente alcalde de la zona del delta y a varios «vecinos-ciudadanos» se les firma a ruego. 
CUADRO 3. Elecciones municipales, San Fernando 1855.

\begin{tabular}{ll}
\hline MARZO (ROBO DE ACTAS) & \multicolumn{1}{c}{ MAYo (NUEVA) } \\
\hline Francisco Fernandez & Augusto Agote (184 votos) \\
Manuel Moura & Angel Crosa (183) \\
Pedro Almondós & Manuel Moura* (152) \\
Lucio Albarracín & Felipe Mabana (141) \\
& Otros candidatos votados \\
& Francisco Fernández* (67) \\
& Lucio Mancini (52) \\
& Pedro Almondos* (51) \\
& José María Belgrano (1) \\
& Carolino Acosta* (1) \\
Sictor Gayán (1) \\
Cosme Alonso & Suplentes \\
Carolino Acosta & Ezequiel Córdoba (cura) (155) \\
& Victor Gayán (151) \\
& Otros candidatos votados \\
& Manuel Moura* (54) \\
& Carolino Acosta* (52) \\
\hline
\end{tabular}

* votados en ambas elecciones. Elaboración personal.

FueNtE: AGN, MGEBA, X 28-8-7, 11455 y ROGEBA, Decreto 22/11/1855.

Los vecinos elegidos en marzo mantuvieron su interés por acceder al cargo de municipal, pero otro grupo cuyos integrantes no habían firmado la defensa de las primeras elecciones, logró desplazarlos. Sin embargo, en junio de 1856 el juez de paz del partido debió insistir ante el nuevo ministro de gobierno, Dalmacio Vélez Sarsfield, por un pedido de nulidad de una elección de cobertura de un cargo. El juez de paz consideraba «un mal precedente (...) la posibilidad de elegir un miembro de la municipalidad en oposición a la voluntad de las 7/octavas partes de los vecinos que son los que tienen mejor conciencia de sus necesidades que una turba de individuos que se hallan accidentalmente en este punto». ${ }^{43}$ Según surgía de los registros, solo unos «veinte vecinos» habían votado y aseguraba el juez que «no querrán verse en el caso de ser obligados a aceptar un candidato que solo podrá traer nuevos conflictos al seno de esa corporación».

El juez de paz finalizaba su explicación encausando el tema en un marco legal y señalando que había considerado su deber declarar que no había elecciones para evitar desórdenes.

43. AGN, MGEBA, X 28-8-7, 13044. 
No pude menos que mirar como indigna la conducta de tres o cuatro vecinos díscolos que apoyados en 30 o 40 hombres ajenos a los intereses de este Pueblo, pretendiesen disponer a su antojo de ellos, y violando así el artículo 60 de la Ley de Municipalidades que exige para ser Elector la condición de ser avecindado.

Más allá de las posibles facciones en el partido y la valoración de los vecinos residentes, los argumentos esgrimidos remitían a cómo delimitar quiénes podían gozar de los derechos políticos, una deliberación central de buena parte del siglo XIX. ${ }^{44}$

\section{Debates sobre las elecciones municipales en las Cámaras Legislativas}

Las elecciones municipales eran reguladas por el «gobierno» con una actuación central del ministro de gobierno de turno, como venimos viendo. No obstante, durante 1855 debates en las cámaras legislativas tuvieron influencia sobre las mismas y permiten comprender la dinámica electoral de ese año. Sintetizamos a continuación discusiones sobre las elecciones de representantes y senadores en la campaña en 1854 y 1855 , y acerca de los dos proyectos presentados sobre la suspensión de las elecciones municipales en mayo y, posteriormente, directamente la supresión de la «instalación» de las municipalidades de campaña en 1855 .

\section{Cuestionamientos a elecciones legislativas en la campaña}

El domingo 25 de marzo se efectuaron las elecciones para diputados y senadores en las secciones de la campaña, quince días después de las municipales. Al mes, fueron aprobadas las de Diputados, correspondiendo un representante por sección, con excepción de la 12. ${ }^{a}$ donde se acordó pedir «informes acerca de las causas que habían influido para que en los partidos de Mar Chiquita y Ajó no hubiesen concurrido» a votar. ${ }^{45}$ Asimismo se comunicó que en el partido de Mercedes (en la 5. ${ }^{a}$ sección) no había tenido lugar la elección por no haber querido los escrutadores formar el acto. ${ }^{46}$

En paralelo, el tratamiento en la Cámara de Senadores correspondió a la elección de un senador para la $4 .^{a}, 5 .^{a}, 7 .^{a}$ y $8 .^{a}$ secciones de la campaña. En este recinto, la falta de realización de la elección en Mercedes generó cuestionamientos diversos: el vecindario había concurrido a votar, manifestando su voluntad de hacerlo, y la falta de reemplazo de

44. Palti, Elias, «Orden político y ciudadanía. Problemas y debates en el liberalismo argentino en el siglo XIX», E.I.A.L., vol. 5, núm. 2, 1994. <http://eial.tau.ac.il/index.php/eial/article/view/1217>.

45. Diputados, 23-04-1855. La 12. ${ }^{a}$ sección comprendía 12 partidos ubicados en la frontera sur ganadera y presentaba un «patrón de asentamiento predominantemente disperso». En 1840, se habían incorporado ocho partidos a la sección aumentando la cantidad de votantes en la última década rosista. Ternavasio, Marcela, «Hacia un régimen...», cit., p. 138.

46. AGN, MGEBA, X 28-5-5, 7297. 
los escrutadores por parte del juez de paz lo había impedido; en los otros partidos de la

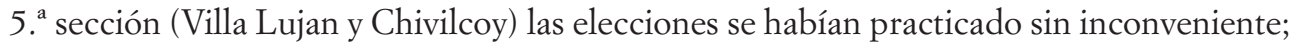
el ganador en la sección había obteniendo 666 votos entre los dos partidos, y en Mercedes habían votado «550 y tantos votos», en la elección anterior, por lo que se estimaba que, de realizarse una nueva elección, no se modificaría el resultado. No obstante el debate, la elección de la 5. a sección también fue aprobada en senadores (11 votos a 3).

Será el 20 de junio cuando se retome en la Cámara de Representantes la aprobación de la elección de un diputado en la 12. ${ }^{a}$ sección, ante la respuesta del juez de paz de Mar Chiquita: el día que debía convocar a elecciones, «llegó la noticia de la invasión de los indios salvajes, y fue preciso poner en armas dicho partido, para ayudar con los demás a la defensa necesaria de la campaña».47 La situación fue categorizada como de «fuerza mayor» y se señaló que «por ningún motivo, debe despojarse a los ciudadanos del derecho sagrado que les concede nuestro modo de ser político». Se discutía, enfatizamos, la tensión entre partido y sección electoral como unidad jurisdiccional, y el derecho a votar en todos los partidos, relación que se potenció ante la posible incidencia en el resultado final de la elección. El llamado a nuevas elecciones en la 12. ${ }^{a}$ tenía que ser de la sección en conjunto (con sus doce partidos): «el acto de la elección es único e indivisible»y, por eso, simultáneo. ${ }^{48} \mathrm{El}$ diputado Torres sostuvo esa postura, especificando que en el resultado había una «aproximación de tres individuos«. En esta oportunidad, la elección no se aprobó ( 25 contra 8). ${ }^{49}$

Otra cuestión a destacar, es la diferente concurrencia de electores en la ciudad y la campaña como rasgo expresado en intervenciones en ambas cámaras. Carecemos todavía de un estudio sistemático sobre los resultados electorales para la campaña y la ciudad durante el Estado de Buenos Aires, pero la información fragmentada que surge en las cámaras pareciera indicar que en estos primeros años la concurrencia en la ciudad disminuyó en general, agudizándose la situación en algunas parroquias en las que no se registraban resultados. ${ }^{50} \mathrm{El}$ cotejo entre ambos ámbitos fue cada vez más frecuente e influyó en la flexibilización de los criterios de aprobación. ${ }^{51}$

A fines de julio, tras discutirse si aprobar o no elecciones en la ciudad que se habían realizado en pocas parroquias, con actos de violencia (se hace referencia a un muerto) y

47. Diputados, 20/06/1855, p. 75.

48. Diputados, 20/06/1855, p. 77

49. Al abordar el caso de Mercedes, varios senadores rememoraron la elección no realizada en el partido de Ajó (sección 12. ${ }^{\text {) }}$ de junio de 1854, buscando establecer criterios comunes. En esa ocasión, las tres candidaturas para senadores tuvieron amplias diferencias de votos entre sí, por lo que la elección fue aprobada. En diputados, los resultados habían sido parejos, por lo que Ajó podría haber definido la sección y se pidió un informe «oficial». Al tratarse el tema semanas después, la elección fue aprobada sin intervenciones. Senadores, 07/07/1854, pp. 31-37. El juez de paz de Ajó se excusaba por haber salido a convocar para las elecciones y ante un «gran temporal» no haber podido regresar para el armado de la votación.

50. Sobre las elecciones en la ciudad, Lettieri, Alberto, «La matriz institucional de la política porteña en tiempos de la «República de la Opinión». Liberales y federales: entre la alianza y el antagonismo (1854-1857)», Estudios Sociales, Santa Fe, 28, 2005, pp. 33-67.

51. Algunas elecciones de la ciudad no fueron aprobadas. Por ejemplo, cuando el senador electo había obtenido 189 votos donde solía superarse los mil votos. 
otros cuestionamientos, se trató el proyecto de aprobación de las elecciones practicadas en las secciones 9. ${ }^{a}$ (dos senadores) y 12. ${ }^{a}$ de campaña (uno). El informante expuso que los electos venían con «una mayoría considerable, lo que prueba que los ciudadanos de la campaña tienen más espíritu público que los de la ciudad». Observó que «solo en el partido de Mulitas», integrante de la 9. ${ }^{a}$ sección con Navarro, Lobos y Monte, el juez de paz no habría podido formar la mesa, por insuficiente número de ciudadanos para ello, y que en la 12. ${ }^{a}$ sección, no habían votado en Pila, Tandil y la Lobería. Finalizaba la presentación de los resultados, fundamentado: «el hecho es que los electos tienen un número de votos que se podría llamar elección canónica. Mil ochocientos un votos constituyen una mayoría considerable».52 Ambas elecciones fueron aprobadas, sin discutir por los partidos faltantes. Cabe aclarar que la cantidad de votantes en estas jurisdicciones de la campaña se encontraba bastante por debajo de los registros de los años 1838 (cuando la sección $12{ }^{a}$ estaba compuesta por cuatro partidos) y 1842 (aunque tampoco se consideraron todos los partidos). ${ }^{53}$

Una tercera cuestión a considerar es la reiteración de falta de votación en determinados lugares de la campaña: el partido de Mercedes o alguno de la sección 12. ${ }^{a}$. La ductilidad de las secciones electorales que permitían intervenciones o estrategias que atemperaban la manifestación de los conflictos, la disminución de votantes o la pluralidad de candidatos, pareciera haber tenido límites en los dos ámbitos señalados, posiblemente porque la población de ambas zonas había tenido gran adhesión al rosismo y, particularmente en Mercedes, al levantamiento federal de diciembre de 1855..$^{54}$ Observaremos, más adelante, lo sucedido en estos partidos al realizarse las elecciones municipales y no poder recurrirse a la posibilidad de suplir los resultados con los de otros.

\section{Suspender las elecciones municipales de mayo}

Tras las elecciones de marzo, faltando dos días para la realización de las nuevas elecciones de municipales en los casos no aprobados de la campaña, el diputado Emilio Agrelo presentó un proyecto para suspenderlas. Sostenía que los jueces de paz de la campaña lo pedían «porque ven el espíritu público, y ven que los Municipales que van a salir electos son los mismos hombres que antes....$^{55}$

Hemos ubicado notificaciones del juez de paz sustituto de San Antonio de Areco, José E. Martínez, solicitando la suspensión por «la exaltación de los ánimos» existente en el partido a consecuencia de las primeras elecciones suspendidas. En este caso, se había hecho uso de «la fuerza» y atropello a «la autoridad» y el juez de paz propietario había

52. Senadores, 27-07-1855, p. 143.

53. La información sobre 1838 y 1842 en, Ternavasio, Marcela, «Hacia un régimen...», pp. 137-138.

54. La adhesión de la zona sur al levantamiento federal posrosista fue más heterogéneo. Barcos, «Tratos, batallas...».

55. Diputados, 03/05/1855, pp. 8-9. 
quedado vinculado, y algunos vecinos se hallaban presos por «Juicios de Imprenta» promovidos en las elecciones. El ministro de gobierno aceptó en este caso la petición, que también generó reacciones encontradas. Se habla de vecinos con exclamaciones de apoyo al leerse la resolución en el pórtico de la iglesia, y del entorno del ex juez de paz Font levantando firmas entre extranjeros y jóvenes para rechazarla. ${ }^{56}$

En la Cámara de Representantes, no se dio lugar al tratamiento del proyecto presentado por Agrelo con argumentos centrados en la falta de precisión sobre las razones, el poco tiempo para efectivizarlo y, fundamentalmente, por corresponderle dicha decisión al gobierno. Como vimos, varias de las elecciones fueron realizadas.

\section{El proyecto de suspensión de la instalación de las municipalidades}

Habiendo pasado diez días desde el rechazo de la cámara de diputados a abordar la suspensión de las elecciones municipales del 6 de mayo, el diputado Agrelo presentó un proyecto directamente de «supresión de la instalación de las municipalidades de campaña» que sí fue debatido. Ya hemos hecho referencia a la consideración del diputado sobre el «espíritu maligno» despertado en la campaña y el «abandono del espíritu publico», en la ciudad —alusiones que aparecen ahora más claras—, pero otras cuestiones merecen ser señaladas.

Varios representantes caracterizaron la situación en términos de «vacío y falta de preparación», remarcando la necesidad de una mejor ley electoral, y de contar con «una organización política de la campaña que ofreciese puntos vigorosos de apoyo al Gobierno» con «Municipalidades dispersas por una vasta extensión de territorio». ${ }^{57}$ Sin embargo, nuevamente se consideraba que le correspondía al gobierno tomar esa decisión:

le hemos visto dejar, sin proceder a la instalación, pasar parte del año 54 y parte del 55; y no ha mucho también le vimos aprobar unas elecciones y desaprobar otras. Quien puede, señor, hacer todo esto, puede aplazar hasta fines de año, que es todo lo que dice el proyecto en cuestión. ${ }^{58}$

Por su parte, buscando dar respuesta tanto a la presión ejercida por los periódicos hacia la instalación de las municipalidades como a la situación del gobierno que ya había dado inicio a las elecciones, el diputado Montes de Oca presentó su propio proyecto. Proponía autorizar al «Poder Ejecutivo para nombrar tanto en la ciudad como en la campaña, los individuos que deben formar la Municipalidad en los años 1855 y 56» y, de manera complementaria, suspender «por igual termino los efectos de la ley de Municipa-

56. AGN, MGEBA, X 28-7-4, 9946. Garavaglia, Juan Carlos, San Antonio de Areco, 1680-1880. Un pueblo de la campaña, del Antiguo Régimen a la modernidad argentina. Rosario, Prohistoria, 2009.

57. Diputados, 16/05/1855, p. 31.

58. Ibidem. 
lidades en cuanto a la elección de los miembros que deben componerla». ${ }^{59} \mathrm{Al}$ fundamentar la propuesta, Montes de Oca señalaba:

que el pueblo no está educado para la planteación (sic) de Municipalidades; quizás muchos ignoran lo que importa un Municipal, cuáles son sus funciones y hasta a quién se deba elegir. Es necesario que se eduque al pueblo para esto; y el Gobierno está en estado de poder nombrar individuos de probidad, honradez y patriotismo, y que reúnan todas las calidades y condiciones necesarias para ese objeto. ${ }^{60}$

Si bien no resultaban novedosas las referencias a la falta de preparación o educación del «pueblo» de la campaña, la propuesta avanzaba sobre la función legitimadora de los procesos eleccionarios. Las elecciones se habían constituido en prácticas indispensable para acceder a determinados cargos y los de «municipales y suplentes» eran parte de ellos, como claramente se expresaba en la normativa, por la prensa y los vecinos. ${ }^{61}$

El diputado Carlos Tejedor, tras la propuesta de Montes de Oca, retomó los argumentos que se venían esgrimiendo en la sesión y sentenció que el último proyecto destruía «completamente la base de las Municipalidades»,

las hace un dependiente de la última clase del Poder Ejecutivo, sin vínculo ninguno con la sociedad de cuyo progreso debe cuidar, en suma, que hace de la Municipalidad unos 400 Jueces de Paz más. ¿Qué se remediará con esto? Desacreditar la institución, como si no la hubiésemos desacreditado bastante con los errores cometidos. ${ }^{62}$

La propia concepción de gobierno municipal se encontraba tensionada como resultado de las dificultades del gobierno en el control de todas las elecciones en la campaña. Agrelo, habiendo conocido «el espíritu de la Cámara», retiró el proyecto.

\section{Preparando la «instalación» de las municipalidades}

En contraste con la intensidad de los tres meses analizados, no encontramos información sobre el proceso de implementación de las municipalidades de campaña entre mediados de mayo y fines de noviembre de 1855 . Podría pensarse que tras el debate en diputados sobre su suspensión hasta 1856, el gobierno estuvo «preparando el terreno», como se instó en la cámara de diputados. No obstante, cierta dilación puede atribuirse al clima de

59. Ibidem, p. 33.

60. Ibidem, p. 34 .

61. Sobre la cuestión de la representación política, las élites y conformación y redefinición del ciudadano, ver Palti, Elias, «Orden político...»; Sábato, Hilda, «Los desafíos...».

62. Diputados, 16/05/1855, p. 34. Esteves Seguí cuestionaba el proyecto de Montes de Oca pero solo dudando de las posibilidades del gobierno de accionar «a 50 leguas de la Ciudad» con «datos que se le suministrasen» sobre las personas a ser nombradas. 
alerta generado ante la presencia de «gente armada», federales exiliados, por la campaña en junio y julio. El 3 de julio en San Nicolás de los Arroyos se habría frustrado un levantamiento similar al supuestamente planeado para la ciudad (la «revolución sofocada», como fue denominada en alguna notificación). En este panorama, junto con la agitación política expresada en torno a las elecciones legislativas en la ciudad y amenazas indígenas (primero puntualmente en Bahía Blanca y luego en la frontera sur), entre otras cuestiones, se propició la renuncia de Irineo Portela como ministro de gobierno y su reemplazo por Valentín Alsina. ${ }^{63}$

La decisión del gobierno por encauzar la «instalación» de las municipalidades de campaña, quedó plasmada con tres decretos del 22 de noviembre, firmados por Alsina y el gobernador Pastor Obligado. En el primero, se estipulaba el domingo 27 de enero de 1856 como fecha para la instalación de las municipalidades en la campaña. ${ }^{64}$ En el segundo decreto se designaba a los municipales y suplentes que integrarían la nueva institución y se promovía el nombramiento de los que faltaban. ${ }^{65}$ Los considerandos recapitulaban que «gran parte» de las elecciones del 11 de marzo habían presentado dificultades de «diversos géneros» y que se había mandado a repetirlas el 6 y 13 de mayo, especificando que estas últimas elecciones no habían sido aprobadas todavía por el gobierno. Asimismo, faltaba resolver las excusaciones de los vecinos, e incluir a quienes se habían ausentado, mudado o fallecido. En un esfuerzo relevante de sistematización («minucioso examen de los voluminosos antecedentes de este asunto»), el gobierno presentó la nomina de los municipales y suplentes de 43 partidos. ${ }^{66}$ Es decir, el decreto incluía a 258 vecinos que habían sido elegidos para formar parte de los elencos de las noveles municipalidades. Asimismo, se solicitaba a los jueces de paz que convalidaran por escrito la aceptación de cada elegido, aunque ya lo hubiese hecho con anterioridad. Todo, las aceptaciones y excusaciones, debía mandarse al gobierno. ${ }^{67}$ Por último, se consideraban las elecciones que no habían sido aprobadas y que debían repetirse, así como las que todavía no se habían realizado. En el tercer decreto, se fijaba el 16 y 23 de diciembre como fechas para las elecciones en los partidos pendientes o para las elecciones parciales en 10 partidos, producto de excusaciones aceptadas.

63. Scobie, J., La lucha por..., p. 145. AGN, X, 28-7-4; 28-7-7; 28-7-9, números varios.

64. Se exceptuaba la instalación en varios partidos del Sud por «extraordinarias circunstancias (...) de resultas de las incursiones de los bárbaros». En los partidos donde no se instalaran las municipalidades seguirían, o se formarían, las Comisiones Municipales centradas en el juez de paz. ROGEBA, 22/11/1855, pp. 137 139.

65. ROGEBA, 22/11/1855, pp. 139-146.

66. En el listado se encuentran San José de Flores, Morón, Matanza, San Isidro, San Fernando, Las Conchas, Quilmes, San Vicente, Cañuelas, Ensenada, Magdalena, Villa de Luján, Chivilcoy, Pilar, Exaltación de la Cruz, Zárate, Fortín de Areco, Giles, Chascomús, Ranchos, Monte, Lobos, Navarro, Bragado, Saladillo, 25 de mayo, Baradero, San Pedro, San Nicolás de los Arroyos, Arrecifes, Salto, Pergamino, Rojas, Junín, Dolores, Pila, Ajó, Tuyú, Vecino, Tandil, Tapalqué, Azul, Las Flores. ROGEBA, 22/11/1855, pp. 140-145.

67. Efectivamente, los 47 legados de los juzgados de paz «sobre elecciones municipales» agrupan aceptaciones, excusas y demás notificaciones enviadas al ministro de gobierno. AGN, MGEBA, X, 28-8-7 (11448 a $11455), 28-8-8$ (11456 a 11469), 28-8-9 (11470 a 11491) y 28-8-10 (11492 a 11494). 
¿Cuál era la situación de los partidos de San Antonio de Areco y Villa de Mercedes con elecciones «seriamente reclamadas y protestadas» y, por lo tanto, pendientes desde marzo? Con anterioridad, hemos señalado el caso de San Antonio de Areco y la solicitud de suspensión de las nuevas elecciones municipales de mayo por continuar las tensiones en el partido. En el caso de la villa de Mercedes, tras las elecciones realizadas en marzo, 34 vecinos presentaron una petición en la que expresaban la falta de «libre elección por medio del sufragio espontáneo y sin coacción». ${ }^{68}$ Mientras que los que firmaban se habrían abstenido «de dar dirección a la opinión pública, en la certeza de su infalible fallo», «uno que otro ambicioso» queriendo alcanzar «a toda costa un puesto al que no es llamado obtener por sus antecedentes ni por su posición» habían presionado a los concurrentes para que se los votara. El gobierno aceptó el reclamo pero la nueva elección no se realizó en el mes de mayo, como sucedió en otros partidos. Recordemos que quince días después de las elecciones municipales, la elección para diputados y senadores no se concretó en Mercedes, pese a la concurrencia de votantes, por ausencia de los integrantes de la mesa electoral, posiblemente buscando evitar que se repitiera la situación. Es decir que en el partido que había sido epicentro del levantamiento federal de diciembre de 1852 no se concretó elección alguna desde marzo de 1855 hasta mediados de diciembre, y la de marzo no fue aprobada.

Finalmente, al hacerse la elección en diciembre, hubo 926 votos distribuidos entre 13 candidatos (casi el doble de votos de lo estimado posible para las legislativas), lo que confirmaría el interés por acceder a los cargos municipales y la vigente puja de poder en Mercedes. De los seis municipales y suplentes electos, cuatro eran los vecinos que habían encabezado con sus firmas el pedido de nulidad de la primera elección. ${ }^{69}$

Por su parte, los partidos de Patagones y Bahía Blanca (sección electoral 13. ${ }^{a}$ y 14. , respectivamente) presentaban características particulares en tanto enclaves en territorio indígena, con gran presencia militar, y alejadas no solo de Buenos Aires sino de otros asentamientos de frontera. ${ }^{70}$

Por último, señalamos algunas primeras observaciones sobre las excusaciones de vecinos electos. ${ }^{71}$ Como era posible estimar, se incrementaron al actualizar la confirmación de los electos en marzo, mayo o diciembre, junto con las elecciones parciales para completar los cargos faltantes. En 1855, algunos vecinos elegidos parecieran sorprenderse por haberlo sido, lo que deja para profundizar la forma en que fueron seleccionados los

68. AGN, MGEBA, X, 28-7-5, 10105.

69. AGN, MGEBA, X, 28-10-5,13052.

70. Sobre tensiones políticas en ambos partidos hacia 1856, Zubizarreta, Ignacio «Politización y transformaciones sociales en los pueblos de campaña del Estado de Buenos Aires, 1852-1861», en Diálogos Revista Electrónica de Historia, Costa Rica, 19, 2018, pp. 101-125. Asimismo, Lobería y Mar Chiquita, partidos de la frontera sur y sin pueblos, ya habían mostrado dificultades para la realización de elecciones.

71. Eran admisibles las excusaciones fundadas en «enfermedades crónicas o en motivos legales, como lo es la falta de edad o vecindad fija en el partido», pero no podían aceptarse las basadas en «creerse los electos incapaces de desempeñar las respectivas funciones, o en ocupaciones o en conveniencias personales, que todos los habitantes de un partido deben posponer y sacrificar cuando se trata del bien inmediato y directo de ellos mismos». ROGEBA, 22/11/1855, pp. 139-146. 
candidatos, más allá de los líderes de cada grupo o facción. La excusación pareciera ser una de las instancias más individuales de los procesos electorales por estos años, y las denegaciones realizadas por Alsina, en tanto ministro de gobierno, apelaron justamente a los compromisos comunitarios de la vecindad. Aunque fuese denegada su excusación, el vecino no siempre asumió el cargo.

\section{La «instalación» de las municipalidades a principios de 1856}

Las fechas propuestas por el gobierno para finalizar gran parte de las elecciones e implementar finalmente las municipalidades de campaña en diciembre y enero, no constituyeron un período tranquilo en el Estado de Buenos Aires. Nuevamente, hubo una conjunción de malones indígenas que desde septiembre parecieran haber tenido mayor intensidad haciendo que se incrementaran los pedidos de hombres en la campaña para enfrentarlos, junto con avances de los exiliados desembarcando en puntos alejados entre sí dentro de Buenos Aires desde diciembre. ${ }^{72}$

Si bien estos movimientos ameritan ser revisitados por la historiografía para justipreciar su impacto, los partidos cercanos a la costa de Buenos Aires y particularmente la zona norte (cercana al puerto de Rosario donde los exiliados estaban reclutando gente), parecieran haber sido los más movilizados. La villa de Luján y San Pedro aparecen como pueblos afectados de manera directa, aunque en varios partidos hubo movilización de hombres y recursos, y envíos de sospechosos «anarquistas» u hombres vinculados a posibles «sublevaciones» o uniones con los federales. A principios de febrero, el ministro de gobierno envió una circular a los jueces de paz «sobre el aniquilamiento de los mashorqueros» que habían entrado por Zarate. ${ }^{73}$

En este contexto, no sorprende ubicar notificaciones como la del juez de San Pedro al ministro de gobierno señalando la conveniencia de suspender la instalación de la municipalidad mientras durara el «estado bélico actual» (12 de enero); la del juez de paz del partido de Ensenada informando a principios de febrero que no ha podido «instalar la Municipalidad de Ensenada» «a causa del estado de alarma en que ha permanecido la Campaña en los últimos días», a lo que Alsina propuso hacerlo el siguiente día festivo; o desde el partido de Vecino planteando el avance de los indios. ${ }^{74}$

Lo que más puede llamar la atención es que, en simultáneo, otros los jueces de paz siguieron remitiendo al ministro la aceptación de municipales y suplentes en cada partido, o que, en enero, se empezó a solicitar la aprobación de las actas de la instalación de la

72. AGN, MGEBA X, 28-8-5 (11370, 11372 y 11377). Los líderes federales José María Flores y los coroneles Bustos, Lamela y Olmos penetraron a Buenos Aires, mientras Hilario Lagos y Jerónimo Costa esperaban en Montevideo. Ya en octubre se había producido un intento de invasión. Scobie, J., La lucha por..., pp. 146148 .

73. AGN, MGEBA, X, 28-8-5 al 28-8-10.

74. AGN, MGEBA, X, 28-8-11, 11543. 
municipalidad (Morón), para continuar en febrero desde Luján, Pila, Mercedes, Barracas del Sur, San Fernando, Zarate, Las Conchas, entre otras. No obstante, el 14 de marzo el ministro reiteró el decreto sobre la «instalación de las municipalidades», mientras se seguían enviando actas desde los partidos. Las municipalidades, con sus integrantes electos, se fueron estableciendo con modalidades y agendas propias. ${ }^{75}$

\section{Conclusiones}

Las primeras elecciones de municipales y suplentes que llevarían a la implementación de las nuevas formas de gobierno local en los más de 40 pueblos de la campaña, no pasaron desapercibidas en 1855. Para el gobierno y las cámaras legislativas existía consenso sobre la complejidad del proceso en estos primeros años del Estado de Buenos Aires. Las discusiones en la cámara de diputados sobre los proyectos de modificación de fechas de elecciones y de postergación de su implementación, sin haberlos convalidado, consolidaron las prerrogativas del gobierno en tal sentido.

Un límite hacia el gobierno fue el sostenimiento para los municipales y suplentes de la legitimidad que las elecciones otorgaban a los representantes para ocupar sus cargos, como venía sucediendo con otros cargos desde el proceso posrevolucionario y de reconocimiento de la soberanía popular. No obstante, el principio no era incuestionable en el inicio de la implementación de las municipalidades, aunque sí respetado por las voces líderes de los legisladores que lo diferenciaron de la figura del juez de paz.

El concepto de «instalación» de las municipalidades utilizado por los integrantes del gobierno y de las cámaras legislativas denota tanto una perspectiva centralista que se formalizó en la legislación sobre el tema, como la presunción de un accionar del gobierno en un «vacío» o en comunidades sin experiencias o conocimientos para asumir la nueva forma de gobierno local que se expresó en los debates parlamentarios. Sin embargo, la complejidad aludida por ellos mismos significaba, en parte, tener que enfrentarse al papel activo y plural de los habitantes de la campaña en la organización de cada municipalidad, junto con la coyuntura política más amplia de la etapa posrosista. En este sentido, hemos visto al gobierno tomar decisiones y articular estrategias, tanto como a las autoridades locales, grupos de vecinos y de residentes en la campaña, y considerado las posibles influencias de las incursiones de grupos liderados por federales exiliados en Buenos Aires y los avances de parcialidades indígenas

El gobierno aprobó tres cuartas partes de las elecciones municipales llevadas a cabo en marzo de 1855. La importante proporción no se condice con los pedidos de suspensión realizados al mes y medio siguiente en la cámara de diputados, ni con las expresiones de temor a que volvieran los mazorqueros. Al detenernos en algunas de las elecciones aprobadas, se puso de manifiesto que éstas no necesariamente estuvieron carentes de

75. AGN, MGEBA, X, 28-8-13, 11702, 11703, 11727, entre otros. Canedo, Mariana, «La instalación...». 
tensiones. Tanto en San Nicolás de los Arroyos como en Cañuelas, dos partidos donde predominaban adhesiones políticas diferentes, se hicieron presentes las manifestaciones de interés por las elecciones para municipales por parte de personas o grupos vinculados al rosismo en un pasado inmediato. En ambos casos, los procederes de los jueces de paz en coordinación con diferentes integrantes del gobierno resultaron centrales (corrimiento de fechas, intercambio de información, enrolamiento a quien lideraba la protesta, etc.). La comunicación personal, paralela, entre el juez de paz de Cañuelas y el gobernador Obligado recupera, además, alusiones a reuniones en donde se expresaba la importancia que se daba al resultado de estas elecciones municipales, que debían ser «completamente de hombres nuestros».

Tras una primera y mayoritaria tanda con elecciones aprobadas, los casos más conflictivos quedaron circunscriptos para la realización de un nuevo comicio. En varios de ellos se pusieron en evidencia límites en el accionar del juez de paz y, posiblemente, lo contingente de algunas consideraciones. Los cuestionamientos a las listas no siempre fueron acompañados en los nuevos resultados o por lo menos en forma completa, como lo evidencian la reiterada elección del último juez de paz durante el rosismo en San José de Flores; las dificultades para sostener los desplazamientos de candidatos, en las siguientes elecciones; y, la sustitución del juez de paz por el cuestionamiento de su proceder por parte de los vecinos destacados de su comunidad, sin modificar casi la lista de municipales electos.

A través de las peticiones al gobierno, grupos de vecinos de Las Conchas y Mercedes impugnaron elecciones o, como en San Fernando, intentaron evitar su anulación. En los tres casos los reclamos coincidían en hacer justicia y cuestionaban actuaciones en el acto electoral; algunos más que una solicitud, presentaron un reclamo sobre lo que consideraron sus derechos. Las respuestas no se equipararon. El gobierno acompañó a los nueve vecinos de Las Conchas y a los 37 de Mercedes que reaccionaron ante procederes y resultados no esperados, mientras que los 87 vecinos de San Fernando, no lograron que se respetara el resultado obtenido y quedaron desplazados en la nueva convocatoria.

Los fundamentos esgrimidos en las peticiones abren la perspectiva a las tensiones sociales, que ameritan ser profundizadas, y evidencian divisiones en clave que discute la amplitud de los derechos políticos en esos años (vecinos y habitantes; extranjeros y «del lugar»), así como la representatividad autoimpuesta de algunos vecinos que presumía de conocer las «necesidades de la municipalidad» y buscaba desplazar a los otros por incapacidad o desconocimiento. Estos posicionamientos de exclusión social y política no se diferenciaban demasiado de los expresados en las cámaras legislativas hacia la campaña en general.

La mirada en conjunto de las discusiones en las cámaras sobre la aprobación de las elecciones legislativas en la campaña mostró una mayor ductilidad política de la sección electoral que de los partidos para ajustar los resultados, aunque en algunos casos se presentaron limitaciones por la fuerte adhesión federal, y en partidos de la zona sur con una combinación de ataques indígenas, lejanía y, posiblemente, resultados adversos al gobierno. Otro aspecto considerado fue el cotejo realizado entre las elecciones de la ciudad, 
con menos votantes que en años anteriores y pocas parroquias representadas, y las de la campaña que, pese a posiblemente disminuir el número de votantes en algunos partidos, se volvieron menos observadas por su supremacía numérica.

El gobierno contó con prerrogativas sobre las elecciones e implementación de las municipalidades, pero no pudo controlar los tiempos de las amenazas o ataques indígenas ni las incursiones de los exiliados federales. Posiblemente, éstos representaban «el espíritu maligno» despertado en la campaña que señalaba el diputado Agrelo, junto con la presencia de ex rosistas en las listas de los partidos desde principios de año. Durante todo 1855 y parte de 1856, se fueron resolviendo las primeras elecciones de municipales, aunque las diferentes tensiones sociales y políticas que influyeron en ellas no quedaron zanjadas. No obstante, la adhesión a la conformación de municipalidades desde los pueblos rurales y desde la ciudad primó sobre la coyuntura, y constituyó una parte novedosa de la experiencia soberana de gobierno del Estado de Buenos Aires.

\section{Fuentes}

Diario de Sesiones de la Cámara de Diputados del Estado de Buenos Aires (Diputados), Actas de la sesiones de 23 de abril, 3 de mayo, 16 de mayo, 20 de junio, 3 de julio de 1855, Buenos Aires, Imprenta Americana, 1856.

Diario de Sesiones de la Cámara de Senadores del Estado de Buenos Aires (Senadores), Actas de la sesiones de 7 y 27 de julio de 1855, Buenos Aires, Imprenta Americana, 1857.

Registro Oficial del Gobierno de Buenos Aires (ROGBA), Constitución del Estado de Buenos Aires (1854), Buenos Aires, Imprenta de Mayo, 1855.

Registro Oficial del Gobierno del Estado de Buenos Aires (ROGEBA), decretos de 9 de febrero, 11 de abril, 22 de noviembre de 1855, Buenos Aires, Imprenta de Mayo, 1856.

Archivo General de la Nación (AGN), Archivo del ministro de gobierno del Estado de Buenos Aires (en adelante MGEBA), Sala X, 28-5-5 (legajo 7297); 28-6-14 (9577, 9607; 9631), 28-7-4 (9946); 28-7-5 (10105); 28-8-5 (11370, 11372 y 11377); 28-8-7 (11453, 11455, 13044,11448 a 11455); 28-8-8 (11456 a 11469), 28-8-9 (11470 a 11491), 28-8-10 (11492 a 11494), 28-8-11 (11543), 28-8-13 (11702, 11703, 11727), 28-10-5 (13052, 13075)

\section{Bibliografía}

Aramburo, Mariano, Concepciones en torno a la conformación del Estado, Buenos Aires 1852-1862, Tesis doctoral, UBA, 2015.

Barcos, Fernanda, «Expresiones políticas y movilización popular en los pueblos de la campaña de Buenos Aires. La Guardia de Luján y el Sitio de Lagos (1852-1854)», Nuevo Mundo, Mundos Nuevos, 2012 (en línea) Consultado el 24 de mayo de 2017, pp. 1-19.

-, «Tratos, batallas y malones. El accionar indígena en la frontera sur durante el sitio a la ciudad de Buenos Aires», Corpus, vol. 7, núm. 1, 2017, pp. 2-30.

Caetano, Gerardo (coordinador), Historia conceptual. Voces y conceptos de la política oriental (1750-1870), Montevideo, Ed. De la Banda Oriental, 2014, 2. ${ }^{\text {a }}$ edición 
Caletti Garciadiego, Bárbara, «Después de la tormenta cla calma?: Ejército y milicias en la campaña porteña tras Caseros», Coordenadas, 1, 2014, pp. 59-89.

Cancini, Leonardo, Frontera, militarización y política armada. La Guardia Nacional de la Provincia de Buenos Aires durante la construccion del Estado Nacional (1852-1880), La Plata, AAAPBA, 2017.

Canedo, Mariana, «Pueblos frente al río. Comercio fluvial, poder colonial, y derechos a la tierra Buenos Aires, 1770-1820», Bibliográphica Americana. Revista interdisciplinaria de Estudios coloniales, núm. 8, 2012, pp. 69-93.

—, «Los «pueblos de españoles», en la monarquía hispánica. La ampliación de jurisdicciones hacia el autogobierno (Buenos Aires, siglo XVIII y primeros años del XIX)», en Revista Probistoria, núm. 25, Rosario, 2016, pp. 3-27.

—, «La instalación de las municipalidades de campaña en el Estado de Buenos Aires. Un análisis desde sus actas de sesiones (1856-1858)», Revista de Historia Americana y Argentina, Mendoza, UNCuyo, 2019, pp. 177-209.

Ciliberto, Valeria, «Patrimonio y producción en los entornos rurales de Buenos Aires. San José de Flores, 1800-1875», Mundo Agrario, núm. 15, La Plata, 2007, pp. 34-56.

de Jong, Ingrid y Ratto, Silvia, «La construcción de redes políticas indígenas en el área Araucopampeana: la Confederación indígena de Calfulcurá (1830-1870)», Intersecciones, 9, Olavarría, 2009, pp. 241-260;

Di Meglio, Gabriel, Mueran los salvajes unitarios. La Mazorca y la política en tiempos de Rosas, Buenos Aires, Sudamericana, 2007.

—, «Patria», en Golman, Noemí, Lenguaje y revolución. Conceptos políticos claves en el Río de la Plata, 1780-1850, Buenos Aires, Prometeo, 2008.

Etchechury-Barrera, Mario e Ignacio Zubizarreta (coord.), «Aquí no hay partidos»: Estudios y perspectivas sobre las facciones y grupos políticos del siglo XIX hispanoamericano», Illes e imperis, núm. 17, 2015, pp. 7-17.

Eujanian, Alejandro, El pasado en el péndulo de la política. Rosas, la provincia y la nación en el debate político de Buenos Aires, 1852-1861, Bernal, Universidad Nacional de Quilmes, 2015, pp. 119-139.

Fradkin, Raúl y Jorge Gelman, Juan Manuel de Rosas. La construcción de un liderazgo político, Buenos Aires, Edhasa, 2015, pp. 325-328.

Galimberti, Agustín, «Las prácticas electorales coloniales y la conformación de un "habitus" electoral: el Cabildo de la Villa de Luján entre 1771 y 1821», Probistoria, núm. 29, 2018, pp. 43 67.

Garavaglia, Juan Carlos, «Pobres y ricos»: Cuatro historias edificantes sobre el conflicto social en la campaña bonaerense (1820/1840)», en Poder, conflicto y relaciones sociales. El Rio de la Plata, XVIII-XIX, Rosario, Homo Sapiens, 1999, pp. 29-56.

—, «Manifestaciones iniciales de la representación en el Río de la Plata: la Revolución en la laboriosa búsqueda de la autonomía del individuo (1810-1812), Revista de Indias, núm. 23, Madrid, 2004, pp. 349-382.

—, «Elecciones y luchas políticas en los pueblos de la campaña de Buenos Aires: San Antonio de Areco (1813-1844)», en Boletín del Instituto de Historia Argentina y Americana «Dr. E. Ravignani, núm. 27, Buenos Aires, 2005, pp. 49-73.

-, San Antonio de Areco, 1680-1880. Un pueblo de la campaña, del Antiguo Régimen a la modernidad argentina. Rosario, Prohistoria, 2009. 
- La disputa por la construcción nacional argentina. Buenos Aires, la Confederación y las provincias (1850-1865), Buenos Aires, Prometeo, 2015.

Gelman, Jorge, «Crisis y reconstrucción del orden en la campaña de Buenos Aires. Estado y sociedad en la primera mitad del siglo XIX», Boletín del Instituto de Historia Americana y Argentina «Dr Ravignani, núm. 21, 2000, pp. 7-31.

—, «Unitarios y federales. Control político y construcción de identidades en Buenos Aires durante el primer gobierno de Rosas, Anuario IEHS, núm. 19, 2004, pp. 359-391.

González Bernaldo, Pilar Civilidad y política en los orígenes de la nación argentina, Buenos Aires, Fondo de Cultura Económica, 2007, pp. 220-224.

Lanteri, Sol, «¿Una frontera bárbara y sin instituciones? Elecciones y clientelismo en la formación del Estado provincial durante el gobierno de Rosas», Prohistoria, núm. 12, Rosario, 2008, pp. $15-40$.

Lettieri, Alberto, «La matriz institucional de la política porteña en tiempos de la «República de la Opinión». Liberales y federales: entre la alianza y el antagonismo (1854-1857)», Estudios Sociales, Santa Fe, 28, 2005, pp. 33-67.

Palti, Elias, «Orden político y ciudadanía. Problemas y debates en el liberalismo argentino en el siglo XIX», E.I.A.L., vol. 5, núm. 2, 1994 <http://eial.tau.ac.il/index.php/eial/article/view/1217> .

Pérez, Mariana En busca de mejor fortuna. Los inmigrantes españoles en Buenos Aires desde el Virreinato a la Revolución de Mayo, Buenos Aires, Prometeo-UNGS, 2010.

Sábato, Hilda, «Los desafíos de la República. Notas sobre la política en la Argentina pos Caseros», Estudios Sociales, núm. 46, 2014, pp. 77-117.

Santilli, Daniel, «El unanimismo en la campaña. Las actividades políticas en la zona rural de Buenos Aires entre Rivadavia y Rosas. Quilmes, 1821-1839», Probistoria, núm. 12, Rosario, 2008, pp. 41-67.

Scobie, James, La lucha por la consolidación de la nacionalidad argentina, 1852-1862, Buenos Aires, Solar-Hachette, 1964.

Ternavasio, Marcela, La revolución del voto. Política y elecciones en Buenos Aires, 1810-1852, Siglo XXI, Buenos Aires, 2002.

—, «Hacia un régimen de unanimidad. Política y elecciones en Buenos Aires, 1828-1850», en Sabato, Hilda (coordinadora), Ciudadanía politica y formación de las naciones. Perspectivas históricas de América Latina, FCE-Colegio de México, 2004, pp. 119-141.

Zubizarreta, Ignacio «Politización y transformaciones sociales en los pueblos de campaña del Estado de Buenos Aires, 1852-1861», en Diálogos Revista Electrónica de Historia, Costa Rica, 19, 2018, pp. 101-125. 
